\title{
Caracterização mineralógica do túnel da PCH Garça Branca e a primeira ocorrência de analcima no estado de Santa Catarina, Brasil
}

\author{
Mineralogical characterization of the tunnel of the PCH Garça Branca \\ and occurrence of analcime in the state of Santa Catarina, Brazil
}

\section{Anísio Cláudio Rios Fonseca1; Rodrigo Del Olmo Sato²; Maurício Thadeu Fenilli de Menezes $^{3}$; Alexandre Cláudio Rios Fonseca ${ }^{1}$}

${ }^{1}$ Centro Universitário de Formiga, Minas Gerais (MG), Brasil.

${ }^{2}$ Universidade do Extremo Sul Catarinense - UNESC, Criciúma, Santa Catarina (SC), Brasil.

${ }^{3 .}$ Minashidrogeo Recursos Hídricos, Engenharia e Meio Ambiente Ltda. Florianópolis- Santa Catarina (SC), Brasil.

\section{Resumo}

Introdução: Diferentes minerais têm sido encontrados nas cavidades das rochas vulcânicas do Grupo Serra Geral, Bacia do Paraná e no ano de 2016, durante perfuração de um túnel para uma barragem no munícipio de Anchieta- SC, foram encontrados cristais deltoide-icositeraédricos de analcima atapetando cavidades e vesículas nas rochas, associados a outros minerais. Objetivos: Confirmar a identidade do mineral como analcima e definir as fácies minerais na extensão do túnel. Metodologia: Aferição de hábito, dimensões, cor, brilho, traço, fluorescência UV-L, densidade, perda ao fogo, clivagem, fratura, diafaneidade, tenacidade e difração de raios X (DRX). Resultados: Hábito isométrico trapezoédrico icosaedro com dimensões de até cinco centímetros, incolor a branco, translúcido a opaco, brilho vítreo, fratura subconchoidal, clivagem fraca. Na mufla a $300^{\circ} \mathrm{C}$ por 60 minutos torna-se branco e friável. A densidade média é de 2,26 g/ $\mathrm{cm}^{3}$, dureza Mohs 5 a 5,5, traço branco, cor branca, perda ao fogo de 7,95\% e raios X com picos característicos para analcima. Discussão: Ocorre in situ em cinco fácies: Analcima e Mordenita/Escolecita (cristais superficiais e inclusos); Analcimas isoladas euedrais com até $5 \mathrm{~cm}$; Analcima e Estilbita-Ca com marcas de dissolução; Analcima e calcita com hábito trigonal; Analcima e Estilbita-Ca euédrica, maclada e sem dissolução. Conclusão: Os ensaios realizados confirmaram a espécie mineral analcima $\left(\mathrm{NaAlSi}_{2} \mathrm{O}_{6} \cdot \mathrm{H}_{2} \mathrm{O}\right)$ um importante registro da ocorrência no Estado de Santa Catarina.

Palavras-chave: Mineralogia; Serra Geral; Zeólitas; Fácies; Cristais

Autor correspondente:

Anísio Cláudio Rios Fonseca

Endereço: Rua Georges Khoury, 200 - Centenário

Recebido em: 21/10/2020

CEP:35574-114-Formiga (MG), Brasil.

Revisado em: 23/10/2020

Aceito em: 03/02/2021

E-mail:anisiogeo@uniformg.edu.br

Publicado em: 02/03/2021 


\section{Abstract}

Introduction: Different minerals have been found in the cavities of the volcanic rocks of the Serra Geral Group, Parana Basin and in 2016, during the drilling of a tunnel for a dam in the municipality of Anchieta$S C$, deltoid-icositerahedral crystals of analcime were found carpeting cavities and vesicles in the rocks, associated with other minerals. Objectives: Confirm the identity of the mineral as analcima and define the mineral facies in the extension of the tunnel. Methodology: Measurement of habit, dimensions, color, brightness, line, UV-L diffraction, density, loss to fire, cleavage, fracture, crosstalk, toughness and X-Ray difraction (DRX). Results: Isometric trapezoidal icosahedron habit with dimensions of up to five centimeters, colorless to white, translucent to opaque, vitreous luster, subconchoidal fracture, weak cleavage. In the muffle at $300^{\circ} \mathrm{C}$ for 60 minutes it becomes white and friable. The average density is $2.26 \mathrm{~g}$ $1 \mathrm{~cm}^{3}$, Mohs hardness 5 to 5.5, white line, white color, loss of fire of $7.95 \%$ and X-ray with characteristic peaks for analcime. Discussion: Occurs in situ in five facies: Analcime and Mordenite / Scolecite (surface and included crystals); Euchral isolated analcimes up to $5 \mathrm{~cm}$; Analcime and Estilbite-Ca with dissolution marks; Analcime and calcite with trigonal habit; Analcime and Stilbite-Ca euhedral, maclas and without dissolution. Conclusion: The tests performed confirmed the mineral species analcima $\left(\mathrm{NaAlSi}_{2} \mathrm{O}_{6} \cdot \mathrm{H}_{2} \mathrm{O}\right)$, being an important record of the occurrence in the State of Santa Catarina.

Keywords: Mineralogy; Serra Geral; Zeolites; Facies; Crystals.

\section{Introdução}

A Pequena Central Hidrelétrica (PCH) da Garça Branca é uma usina hidrelétrica de pequeno porte situada no rio das Antas, município de Anchieta- SC, é um empreendimento da Garça Branca Energética S/A. Abrange áreas dos Municípios de Anchieta e Guaraciaba em Santa Catarina, com potência instalada de 6,5 MW, atendendo uma demanda aproximada de 45 mil pessoas. A usina está situada no domínio do Grupo Serra Geral, formado por basaltos, basalto- andesitos, riodacitos e riólitos, com intercalações de arenito Botucatu e sedimentos vulcanogênicos constituídos por rochas vulcânicas e intrusões que recobrem 1,2 milhões de $\mathrm{km}^{2}$ da Bacia do Paraná. O evento ocorreu no período Cretáceo, entre 137 e $127 \mathrm{Ma}^{6,7,8,10,12}$.

Localmente ocorre a Formação Paranapanema, limítrofe com a Formação Cordilheira Alta, com idades em torno de 132, 2 m.a. +/- 2 m.a. Ar-Ar ${ }^{12}$. As espessuras dos derrames podem chegar a $1500 \mathrm{~m}$. Na porção sul e central da Bacia do Paraná as porções inferiores das suítes vulcânicas são em geral de composição básica ${ }^{6,7,10,12}$. Em muitos locais, no topo dos derrames. é verificada a ocorrência de rochas ácidas. Abaixo as imagens de recortes do mapa geológico de Santa Catarina com a localização do empreendimento (FIGURA 1). A FIGURA 2 apresenta a imagem de satélite $^{9}$ da obra da hidrelétrica. 


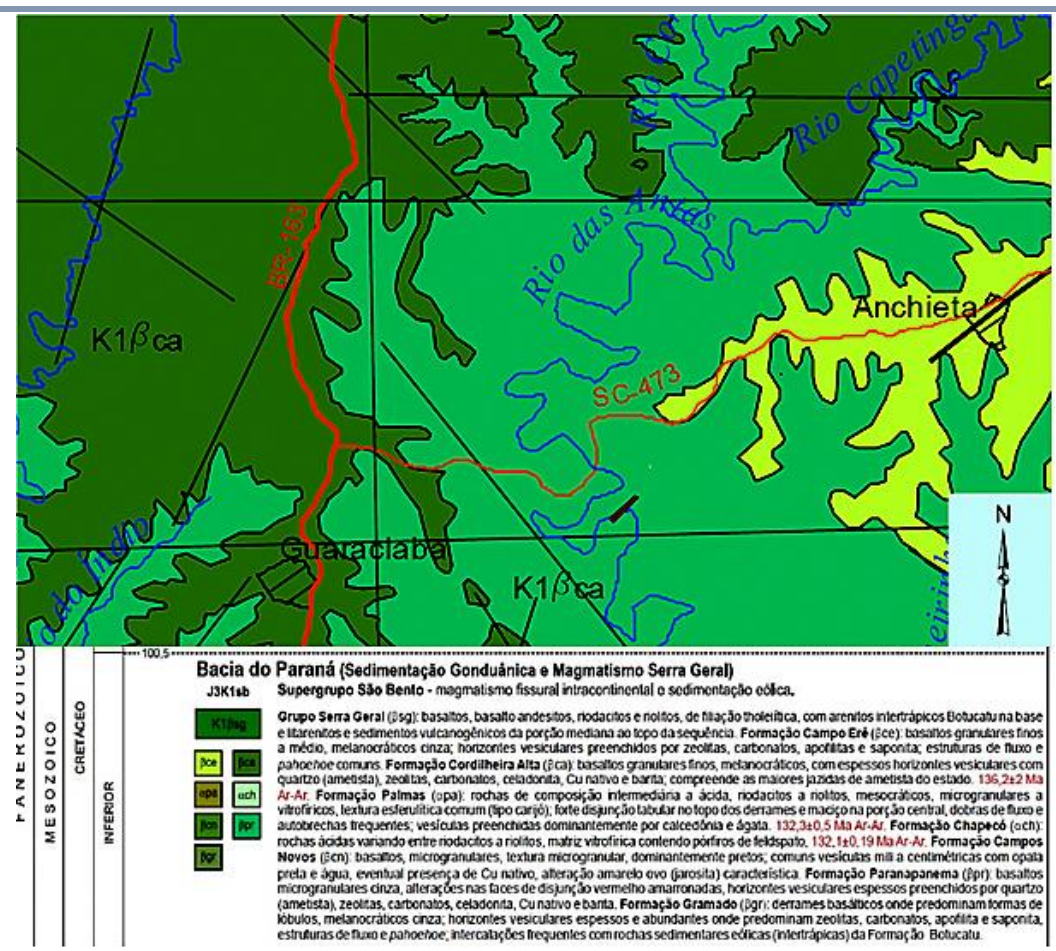

FIGURA 1- Recorte e legenda do mapa geológico do estado de Santa Catarina na escala 1:500000, com marcação da hidrelétrica (traço).

Fonte: http://rigeo.cprm.gov.br/xmlui/handle/doc/17996?show=full

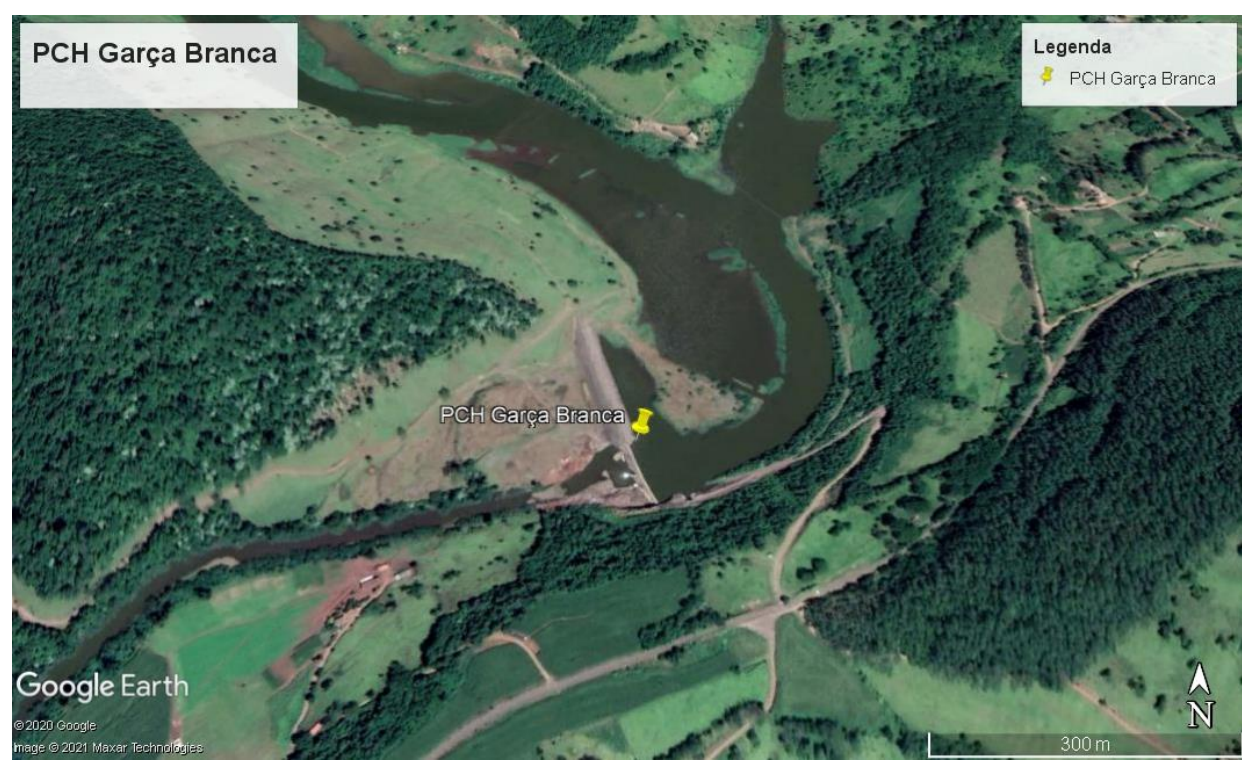

FIGURA 2- Imagem do empreendimento (2019). Escala à direita.

Fonte: Google Earth. Disponível em: https://www.google.com.br/intl/pt-BR/earth/.

O túnel tem 510 m e foi construído em 2016 para ser o conduto forçado da barragem, onde parte da água represada alimenta as turbinas para geração de energia elétrica (FIGURA 3). Durante a perfuração, foram encontradas mineralizações atapetando cavidades e vesículas nas rochas parcialmente intemperizadas. As rochas foram classificadas pela equipe geológica como riólito vesicular, riólito foliado, riodacito amigdaloide, brecha vulcânica. Um dique de diabásio maciço, com espessura de 2 metros, ausente de mineralizações, foi 
encontrado na estaca de $210 \mathrm{~m}$. Os minerais característicos destas cavidades são quartzo, calcita, barita, cobre nativo e zeólitas ${ }^{6,8}$.

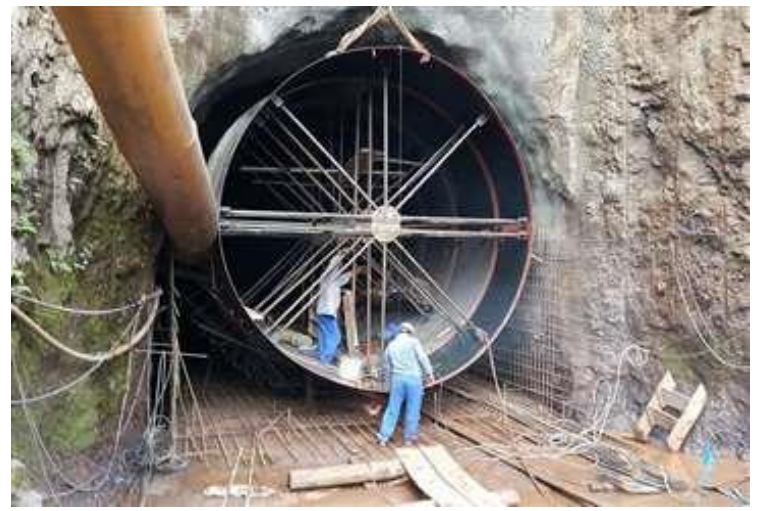

FIGURA 3- Instalação de turbina no túnel onde foram coletadas as amostras.

Fonte: Autores (2020).

A analcima é um mineral da família das zeólitas e foi primeiramente descrita pelo geólogo francês Déodat de Dolomieu (1750-1801), na lava das ilhas ciclópicas perto da Sicília, Itália. Foi nomeada em 1797 pelo mineralogista francês Rene Just Haüy, do grego

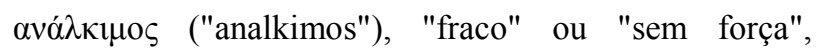
aludindo à carga eletrostática fraca desenvolvida quando o mineral é aquecido ou esfregado ${ }^{2}$. Ela se cristaliza no sistema triclínico- pedial, possui hábito de trisoctaedro tetragonal (ou deltoide-icositetraedro), com dimensões dos cristais variando de milimétricas a mais de $50 \mathrm{~mm}$ em alguns casos e é formada a temperaturas entre $100^{\circ}-180^{\circ} \mathrm{C}$, quando as soluções são extremamente sódicas, com baixo $\mathrm{Ca}$ e pH entre 8,0-12, 1,2,3,8.

A composição ideal é $\mathrm{NaAlSi}_{2} \mathrm{O}_{6} \cdot \mathrm{H}_{2} \mathrm{O}$, com massa molecular de 220,15 g. a composição em percentual de peso é: $\mathrm{Na}_{2} \mathrm{O}-14,08 \%$; $\mathrm{Al}_{2} \mathrm{O}_{3}-23,16 \% ; \mathrm{SiO}_{2}-54,58 \%$; $\mathrm{H}_{2} \mathrm{O}-8,18 \%{ }^{1,2,3,4}, 13$. A FIGURA 4 mostra cristais de analcima em veios e cavidades, e a FIGURA 5 o seu hábito.

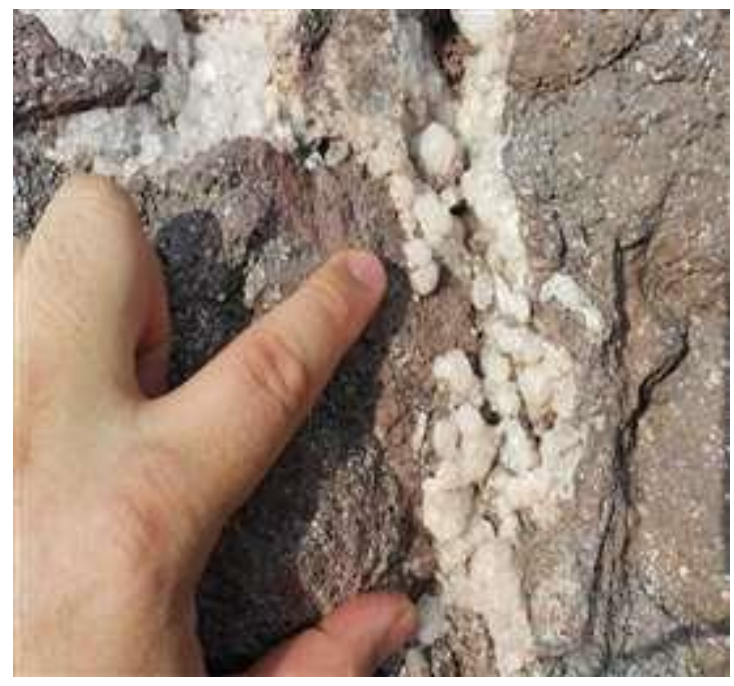

FIGURA 4- Cristais de analcima preenchendo vesículas e fraturas. Cristais medem até $1,5 \mathrm{~cm}$.

Fonte: Autores (2020) 


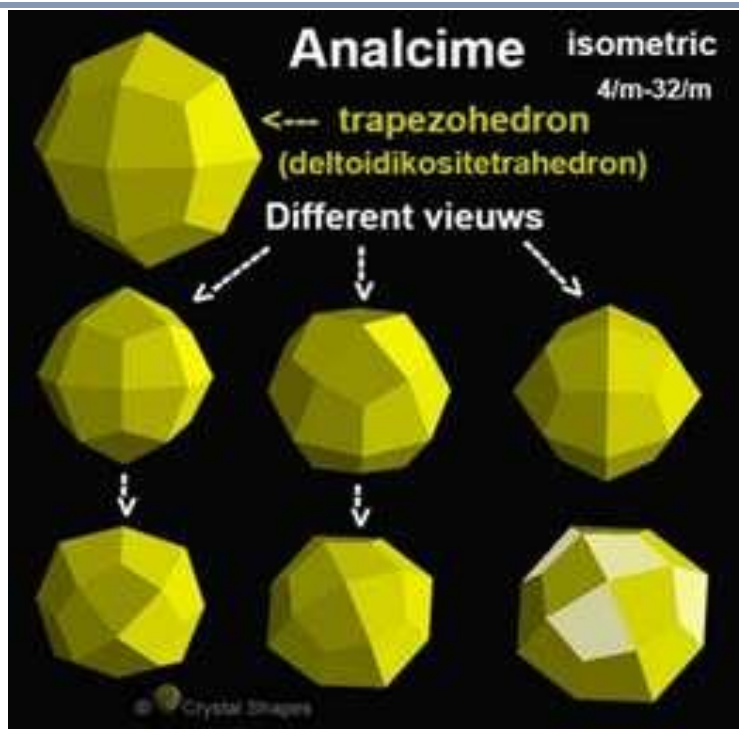

FIGURA 5- Ilustração do hábito da analcima.

Fonte: Disponível em: https://www.smorf.nl/crystal_shapes/

A analcima atapeta cavidades e veios na rocha vesicular formando elegantes associações. Os cristais se encontram implantados na rocha hospedeira com

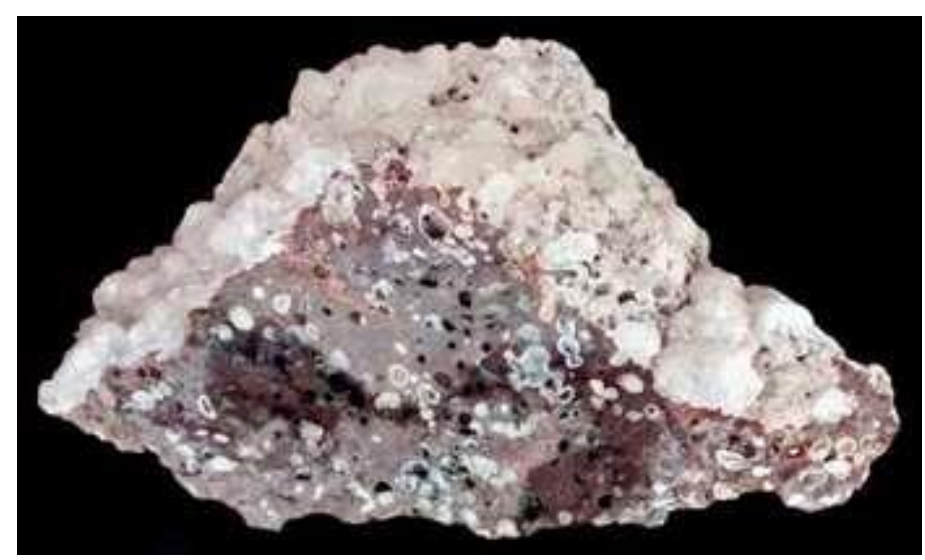

FIGURA 6- Cristais de analcima na rocha vesicular. Amostra com $9 \mathrm{~cm}$.

Fonte: Autores (2020)

Os objetivos deste trabalho foram confirmar a identidade do mineral utilizando técnicas analíticas de laboratório e difração de Raios- x, além de identificar in situ as fácies minerais associadas à analcima na extensão do túnel.

\section{Metodologia}

Análise de parâmetros visuais e físicos como cor, brilho, clivagem e fratura (com partição de amostras), tenacidade (com uso de martelo Estwing), dureza (em placa de vidro), diafaneidade, traço em porcelana fosca supressão das faces da base, formando drusas de indivíduos quase hemisféricos, como na FIGURA 6. 
$\mathrm{m}_{2}$ - Massa do picnômetro com água

$\mathrm{m}_{3}$ - Massa do picnômetro com água e mineral no seu interior do mesmo

A densidade por este método foi calculada através da equação:

$$
\mathrm{d}=\frac{\mathrm{m} 1}{\mathrm{~m} 2-(\mathrm{m} 3-\mathrm{m} 1)}
$$

Para o ensaio de perda ao fogo foram trituradas 55,87 g de amostras. Posteriormente foram pesadas em balança analítica digital e colocadas na mufla, e aquecidas à temperatura de $300^{\circ} \mathrm{C}$ por 60 minutos, para expulsão da água de constituição e posterior cálculo do percentual em massa perdido.

$\mathrm{O}$ ensaio de dureza foi realizado atritando as amostras em uma placa de vidro comum $(20 \times 30 \mathrm{~cm})$ e o ensaio de traço foi realizado atritando o mineral na porcelana (placa de $12 \mathrm{~cm}$ ) para aferição da cor do pó obtido. O ensaio de fluorescência foi realizado em estúdio de $40 \times 30 \mathrm{~cm}$ de madeira revestida internamente por tinta preta fosca e lâmpada de UV-L de $15 \mathrm{~W}$.

\section{Resultados}

A análise in situ revelou que a analcima está cristalizada em cavidades arredondadas ou irregulares de dimensões variadas, associadas às outras zeólitas e calcita. Seu hábito é isométrico trapezoédrico icosaedro formando cristais hemisféricos com dimensões de até cinco centímetros. Sua morfologia indicou primariamente tratar-se de analcima.

Os resultados obtidos apresentaram densidade média de 2,26 $\mathrm{g} / \mathrm{cm}^{3}$, valor bem próximo do preconizado pela literatura $\left(2,24 \text { a } 2,29 \mathrm{~g} / \mathrm{cm}^{3}\right)^{3}$. A dureza foi estimada com utilização de uma placa de vidro $(\mathrm{D}=5,5)$, e foi obtido o valor aproximado de 5 a 5,5 na escala de Mohs.

A perda ao fogo resultou numa diminuição de $4,163 \mathrm{~g}$ da massa inicial, equivalente a 7,45\% em massa. Isto se deu devido à perda de água de constituição, o que associado a valores menores de densidade e sua paragênese, excluiu a possibilidade de o mineral ser leucita, a qual é anidra e muito semelhante morfologicamente.

Os demais resultados foram: Cor: Branca; Fluorescência UV-L: levemente fluorescente em branco; Clivagem: indistinta; Fratura: subconchoidal a estilhaçada; Diafaneidade: translúcido a opaco; Cor do traço (na porcelana fosca): branco; Tenacidade: quebradiço; Brilho: vítreo a nacarado; Diafaneidade: fosco a translúcido.

O resultado da difração de raios $X$ encontra-se na

\section{FIGURA 7.}




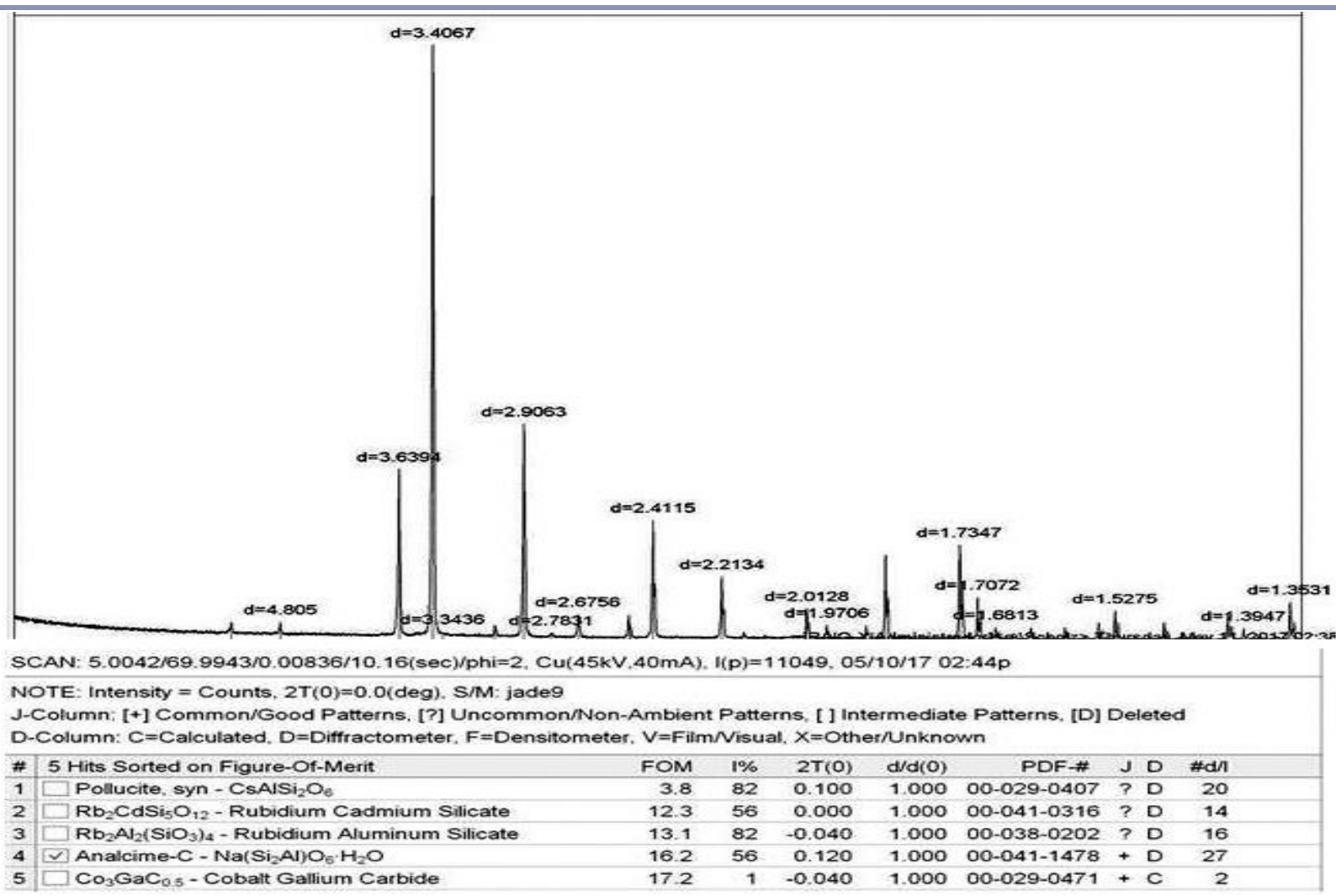

FIGURA 7- Difração de raios X e resultado.

Fonte: Autores (2020).

\section{Discussão}

Os valores e características obtidos nos ensaios, associados aos picos característicos da análise de DRX, correspondem aos elementos composicionais da analcima confirmaram a identidade do mineral encontrado no local da obra.

As rochas encaixantes das mineralizações são rochas vulcânicas extrusivas afaníticas, mesocráticas de composição ácida, pertencentes ao Grupo Serra Geral potencialmente riólitos/riodacitos do tipo Chapecó. Foram encontrados e identificados três litotipos predominantes: Vulcânica Maciça; Auto brecha Vulcânica; Vulcânica vesiculada.

Os minerais associados às analcimas encontrados são frequentes no oeste catarinense. São eles: Calcita $\left(\mathrm{CaCO}_{3}\right), \quad$ Mordenita $\left(\mathrm{Na}_{2} \mathrm{Ca}_{2} \mathrm{KAl}_{2} \mathrm{Si}_{10} \mathrm{O}_{24} .7 \mathrm{H}_{2} \mathrm{O}\right)$, Escolecita $\left(\mathrm{CaAl}_{2} \mathrm{Si}_{3} \mathrm{O}_{10} \cdot 3 \mathrm{H}_{2} \mathrm{O}\right)$ e Estilbita-Ca $\left(\mathrm{NaCa}_{4} \mathrm{Al}_{9} \mathrm{Si}_{27} \mathrm{O}_{72} \cdot \mathrm{nH}_{2} \mathrm{O}\right)$. Foram identificadas in situ cinco diferentes fácies com associações minerais, todas incluindo analcima.

A Fácies 1 é caracterizada por associação de analcima e Mordenita/Escolecita, brancas, aciculares e fibrorradiadas, inclusas e sobre as analcimas, conforme a

\section{FIGURA 8.}




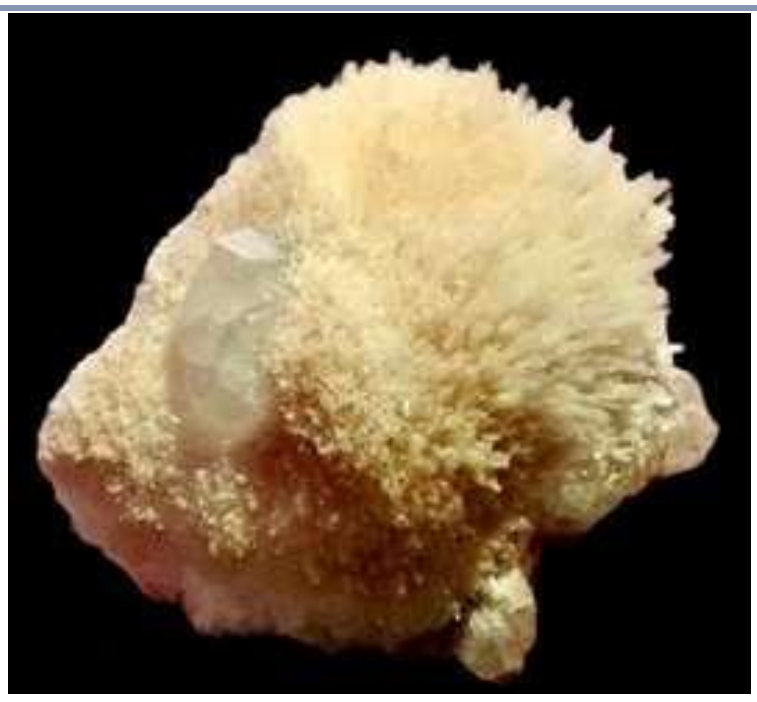

FIGURA 8- Cristais aciculares de Escolecita e Mordenita sobre e inclusos em analcima. Amostra com $5 \mathrm{~cm}$. Fonte: Autores (2020)

A fácies 2 é caracterizada por cristais de analcima euédricos isolados, com dimensões milimétricas e até 5 $\mathrm{cm}$, implantados sobre a rocha hospedeira, translúcidos a opacos e predominantemente brancos (FIGURA 9).

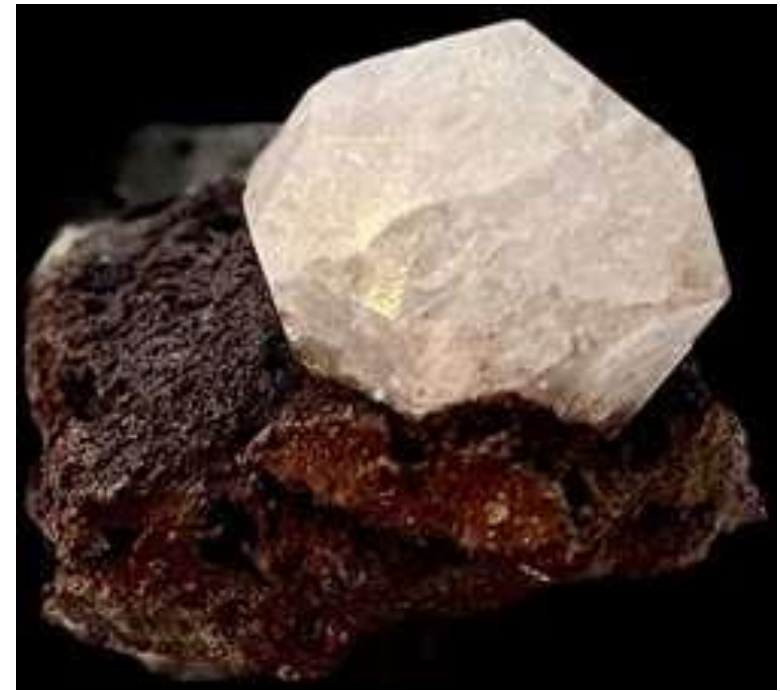

FIGURA 9- Cristal isolados de analcima euédrica. Cristal com 1,3 cm.

Fonte: Autores (2020)

A fácies 3 é caracterizada por cristais de analcima associados à Estilbita-Ca branca com frequentes marcas de dissolução, conforme a FIGURA 10. 


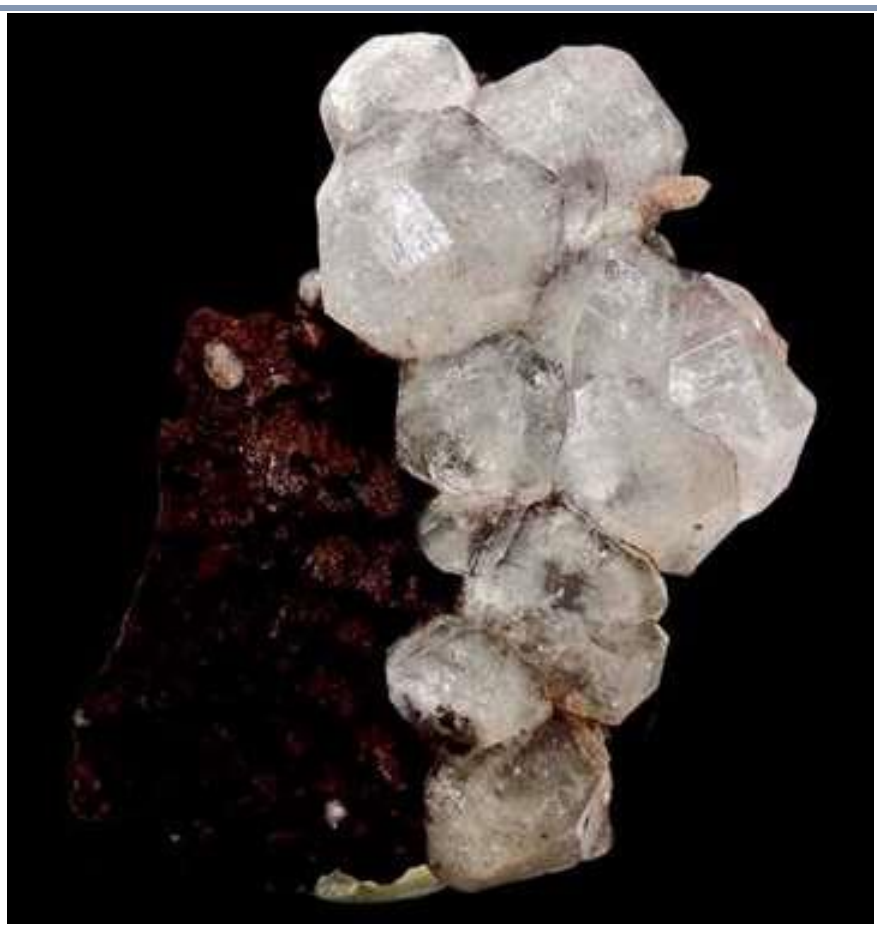

FIGURA 10- Cristais de analcima e estilbita. Amostra com $5 \mathrm{~cm}$.

Fonte: Coleção e imagem de Jhonatan Gomes da Silva (2020)

A fácies 4 é caracterizada por cristais de analcima associados à calcita incolor com hábitos trigonais (prismáticos e bipiramidais de quatro faces) conforme a

FIGURA 11.

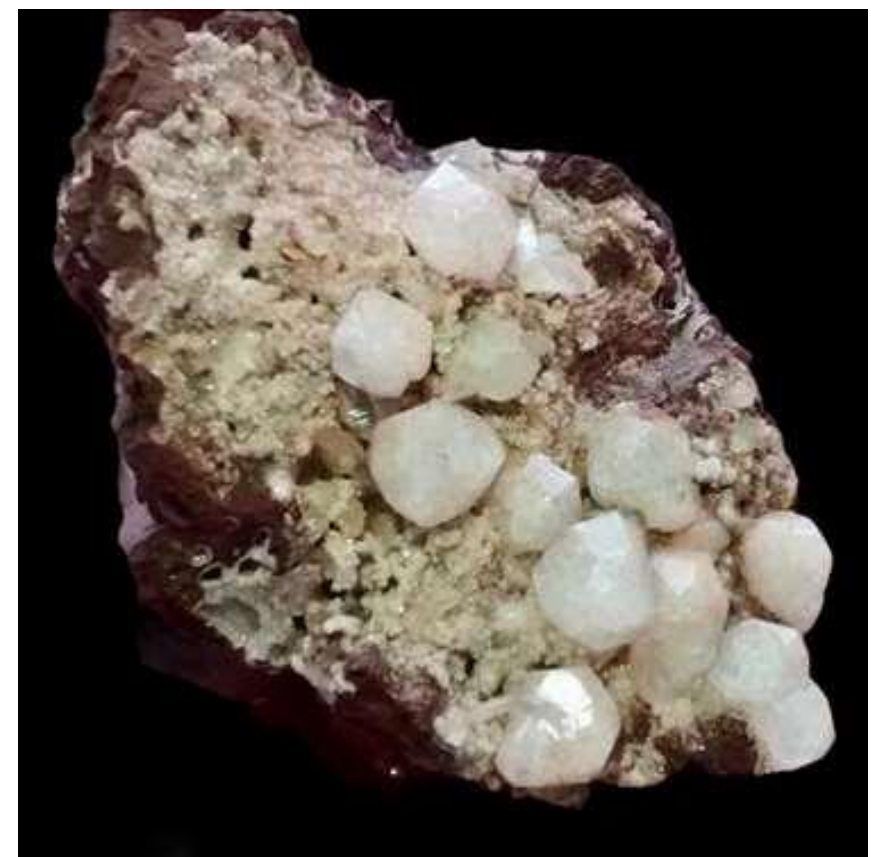

FIGURA 11- Cristais de analcima associados à calcita. Amostra com $9 \mathrm{~cm}$.

Fonte: Autores (2020) 
A fácies 5 é caracterizada por cristais de analcima associada à Estilbita-Ca. Esta última é amarela, euédrica, maclada com hábito gravata borboleta ou ampulheta ${ }^{8} \mathrm{e}$ sem feições de dissolução, conforme a FIGURA 12.

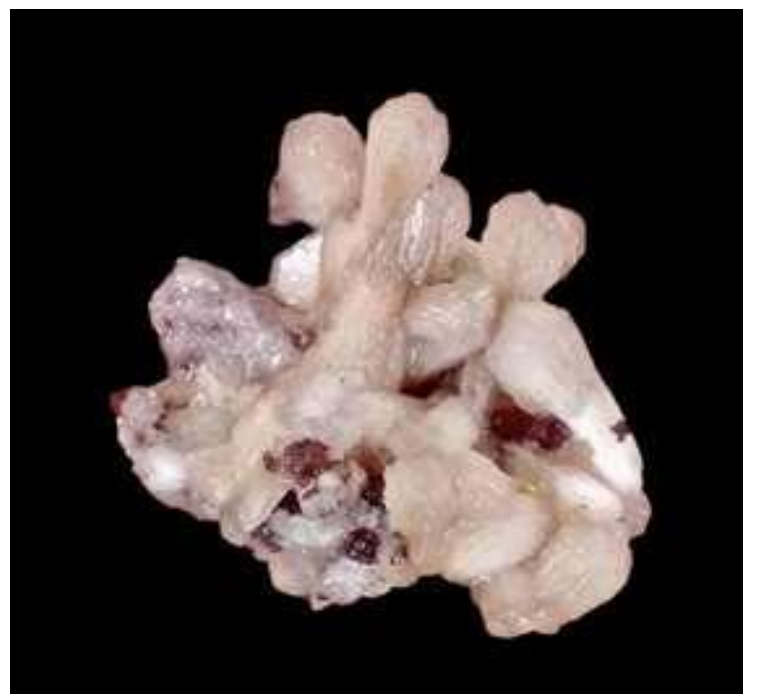

FIGURA 12- Associação de analcima e estilbita. Amostra com 4 cm.

Fonte: Autores (2020)

Cabe registrar a ocorrência de cobre nativo em derrames básicos situados abaixo de uma sequência de derrames contendo analcimas. A FIGURA 13 evidencia o hábito dendrítico da mineralização.

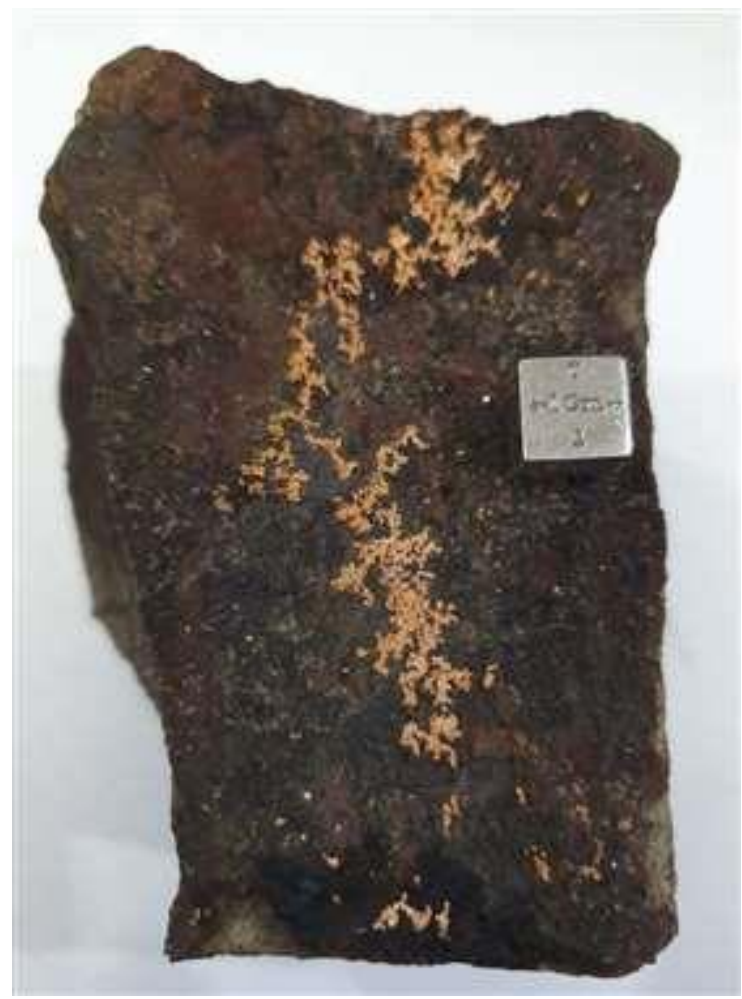

FIGURA 13- Cobre nativo com hábito dendrítico. O cubo de referência ao lado possui $1 \mathrm{~cm}$. Fonte: Autores (2020) 


\section{Conclusão}

O conjunto de métodos analíticos tradicionais com a difração de raios $\mathrm{X}$ possibilitaram a identificação do mineral como analcima $\left(\mathrm{NaAlSi}_{2} \mathrm{O}_{6} \cdot \mathrm{H}_{2} \mathrm{O}\right)$, a qual ocorre em cinco fácies distintas no túnel.

\section{Referências}

1. ANALCIMA. Disponível em: < https://museuhe.com.br/mineral/analcimaanalcime/>. Acesso em: 20/07/2020.

2. ANALCIME. Disponível em: https://www.mindat.org/show.php?id=210\&ld= 1. Acesso em: 17/08/2020.

3. ANALCIME MINERAL DATA. Disponível em:

<http://webmineral.com/data/Analcime.shtml\#. XLfDNIlKjcc>. Acesso em: 17/08/2020.

4. CRYSTAL SHAPES GALLERIES. Disponível em: 〈https://www.smorf.nl/crystal_shapes/>. Acesso em: 20/07/2020.

5. DANA, J.D. Manual de mineralogia. Rio de Janeiro: Livros técnicos e Científicos, 1978. 420p.

6. FERNANDES, A.J. et al. Estratigrafia dos Derrames de Basaltos da Formação Serra Geral (Ribeirão Preto - SP) baseada na Geologia Física, Petrografia e Geoquímica. Geologia USP, v.10, n.2, 2010. Disponível em: http://www.igc.usp.br/geologiausp - 73. Acesso em: $26 / 11 / 2020$

7. FORMAÇÃO SERRA GERAL. Disponível em: https://www.cprm.gov.br/publique/media/gestao territorial/geoparques/aparados_serra/ap_geol pag05.htm. Acesso em: 30/09/2020.

8. FRANK, H.T. Gênese e padrões de distribuição de minerais secundários na Formação Serra Geral (Bacia do Paraná). Universidade Federal do Rio Grande do Sul. Instituto de geociências. Programa de pósgraduação em geociências. 2004.

9. GOOGLE EARTH. Disponível em: https://www.google.com.br/intl/pt-BR/earth/. Acesso em 26/11/2020

10. HARTMAN, L.A. História natural do Grupo Serra Geral desde o Cretáceo até o Recente. Revista do Centro de Ciências Naturais e Exatas - UFSM Instituto de Geociências, Universidade Federal do Rio Grande do Sul, Porto Alegre,
Brasil. Ciência e Natura, Santa Maria, v. 36, Ed. Especial. p. 173-182, 2014.

11. LEINZ, Victor; CAMPOS, J.E. Guia para determinação de minerais. São Paulo: Cia. Editora Nacional, 1976.

12. MAPA GEOLÓGICO DO ESTADO DE SANTA CATARINA. Disponível em: < http://rigeo.cprm.gov.br/xmlui/handle/doc/1799 6? show=full > . Acesso em: 15/08/2020.

13. TSCHERNICH, R.W. Zeolits of the world California: Geoscience Press, 567 p., 1992. 